\title{
DESPUÉS DEL CRIMEN PERFECTO: EL FUTURO DE LA CULTURA EN LA ERA DEL SIMULACRO
}

Jordi Revert Gomis ${ }^{1}$ : Universitat de València. España.

revert.jordi@gmail.com

\section{RESUMEN}

El presente trabajo repasa las ideas expuestas en torno a los conceptos de cultura, simulacro e hiperrealidad desarrolladas por el filósofo Jean Baudrillard a lo largo de su carrera y, en particular, en su libro El crimen perfecto. Las líneas que siguen examinan la vigencia de sus reflexiones en el momento actual, sobre todo en lo que respecta a la relación entre las diferentes manifestaciones culturales con el concepto capital de simulacro propuesto por el francés. Un vínculo en el que la imagen, en tanto que producto y también mediación, juega un papel primordial en la configuración del orden sistémico.

PALABRAS CLAVE:

Jean Baudrillard - simulacro - hiperrealidad - cultura.

\section{AFTER THE PERFECT CRIME: THE FUTURE OF CULTURE IN THE ERA OF SIMULACRA}

\begin{abstract}
This paper reviews the ideas around the concepts of culture, simulacrum and hyperreality developed by philosopher Jean Baudrillard throughout his career and, in particular, in his book The Perfect Crime. The lines that follow examine the validity of his thoughts at the moment, especially in regard to the relationship between different cultural events with the capital concept of simulacrum proposed by the French. A link in which the image, being both a product and mediation, plays a key role in shaping the systemic order.
\end{abstract}

\section{KEYWORDS}

Jean Baudrillard - simulacrum - hyperreality - culture.

\footnotetext{
${ }^{1}$ Jordi Revert Gomis. Máster en Interculturalidad, Comunicación y Estudios Europeos. Universitat de València revert.jordi@gmail.com
} 


\section{DEPOIS DO CRIME PERFEITO: O FUTURO DA CULTURA NA ERA DO SIMULACRO}

\section{RESUMO}

O presente trabalho repassa as idéias expostas em torno aos conceitos de cultura, simulação e hiper-realidade desenvolvidas pelo filósofo Jean Baudrillard ao largo da sua carreira e, em particular, no seu livro $\mathrm{O}$ crime perfeito. As linhas que seguem examinam a vigência de suas reflexões no momento atual, principalmente o que diz respeito à relação entre as diferentes manifestações culturais com o conceito capital de simulacro proposto pelo francês. Um vínculo em que a imagem, como produto e também mediação, joga um papel primordial na configuração da ordem sistêmica.

\section{PALAVRAS CHAVE}

Jean Baudrillard - Simulacro - Hiper-realidade - Cultura

\section{Cómo citar el artículo}

Revert Gomis, J. (2017). Después del crimen perfecto: el futuro de la cultura en la era del simulacro [After the perfect crime: The future of culture in the era of simulacra]. Vivat Academia. Revista de Pedagogía, $\mathrm{n}^{\mathrm{o}}$ 138, 37-55. doi: https://doi.org/10.15178/va.2017.138.37-55 Recuperado de http://vivatacademia.net/index.php/vivat/article/view/993

«¿Por qué no tiene que haber tantos mundos reales como mundos imaginarios? ¿Por qué un solo mundo real, por qué semejante excepción?» (Baudrillard, 1995, p. 89).

\section{INTRODUCCIÓN}

En 1995 Jean Baudrillard publicaba El crimen perfecto, a la postre una de las obras fundamentales de su bibliografía. Fundamental en tanto que esta podía considerarse como síntesis y enésima potencia de la idea de mayor calado y pervivencia del filósofo. La hiperrealidad y el simulacro eran dos conceptos que ya se intuían incluso en su segundo libro, La sociedad de consumo (1970), todavía innominados pero ya presentes bajo un análisis aún atento a la estadística y formalmente aún moderado, pero con puntos de fuga hacia una visión más rabiosa de la realidad que habría de consolidarse en sucesivas publicaciones. Ese discurso baudrillariano ya estaba conformado en sus líneas maestras, por ejemplo, en Cultura y simulacro (1981) ${ }^{2}$, pero aún quedaba lejos de la radicalidad y el estilo abrupto, escrito a golpe de pluma e instinto que caracterizaría El crimen perfecto. Y es en gran medida la concurrencia de esas trazas estilísticas en la escritura con la clarividencia de la exposición que esta propicia la que hace de este último un libro capital en el pensamiento baudrillariano. En él su discurso renueva su compromiso con el desmantelamiento posmoderno de la realidad, pero además redefine la farsa en los términos de una metáfora que podría

\footnotetext{
${ }^{2}$ Del que tomo como referencia la edición original en francés publicada en 1981: BAUDRILLARD, Jean (1981). Simulacres et simulations. París: Éditions Galilée.
} 
resultar definitiva para su entendimiento: el crimen perfecto titular es el de la virtualidad que ha sustituido como un espejismo inalcanzable esa realidad que creíamos inamovible. Y en tanto que inalcanzable la comprobación de si ese espejismo se deshace ante nuestros ojos, nuestros ojos han terminado por aceptar sin sospechas. Nunca existió esa realidad, pero el simulacro nos ha hecho su existencia transparente, cristalina para que no dudemos. Porque su existencia, de hecho, depende de nuestra creencia, sin la cual sería esencialmente imposible. Baudrillard lo explicaba bien con un gag protagonizado por Harpo Marx en Una noche en Casablanca (A Night in Casablanca, Archie L. Mayo, 1946):

En una película de los Hermanos Marx, Harpo se mantiene pegado a una pared. “¿Qué haces ahí?”. “Sostengo la pared”. “¡Te burlas de mí! ¡Sal!”. Harpo da un paso a un lado y la pared se desploma. ¿Acaso no estamos todos pegados a la pared, y ese muro no es el muro de la Realidad? Bastaría con que sólo uno se retirara para que el muro se derrumbara, sepultando a los millones de personas que ocupan ese cuartel abandonado (Baudrillard, 1995, p. 46).

Revisando la escena cabría hacer un par de precisiones, pues Harpo no habla -nunca lo hizo, al menos en el cine- y su interlocutor, un policía que ronda las calles de Casablanca, es quien le obliga a la fuerza a apartarse del muro. Sin embargo, poca importancia tienen estos matices para lo que trata de decirnos Baudrillard. La secuencia sirve como perfecta ilustración de esa tesis central en El crimen perfecto, y de paso sirve para recordar el papel primordial que ocupa la imagen ${ }^{3}$ a la hora de transmitirla, pues la misma tesis no se entiende sin la profusión inagotable de imágenes que ha servido para crear esa ilusión de lo real. La relación entre la imagen y la teoría es intrínseca, y por tanto en ese crimen perfecto aludido por el filósofo es tal debido a la perfección de la imagen misma que lo encubre.

Llegados a este punto, no sorprenderá al lector la advertencia de que las intenciones del presente texto no son las de refutar las ideas expuestas en El crimen perfecto. En parte porque me hallo en sintonía con estas y en parte porque han demostrado una calidad visionaria que parece no tener fin pese al paso de los años, y que por tanto sería inútil contradecir a la vista de la configuración del mundo actual. En ese sentido, los vaticinios del filósofo prácticamente dejaron escrito hasta el final un camino que hoy seguimos recorriendo. Baste recurrir, para comprobarlo, a la última etapa de su bibliografía, a títulos como El intercambio imposible (2002), en el que se aplica su habitual línea teórica sobre temas como la tecnología digital. Lo que en cambio sí propone el presente ensayo es constatar incidencias concretas del simulacro en los procesos mediales y artísticos que delimitan la vida de cualquier individuo integrado en la sociedad de consumo, en la lógica vertiginosa del capitalismo y de las transformaciones no menos vertiginosas que este promueve en su entorno. Y no es que Baudrillard prescindiera en su obra de ejemplos concretos para ilustrar sus

\footnotetext{
${ }^{3}$ Tomaré la imagen en su acepción ligada a una reproducción técnica, en tanto en que es la que mejor se ajusta a un comentario a la obra de Baudrillard. Sin embargo, cabe señalar que hoy en día investigadores como Malena Segura Contrera trabajan en una arqueología de la imagen que buscan deshacer esa vinculación conceptual automática con el medio técnico en la que, como hijos de la modernidad, apenas podemos evitar incurrir.
} 
palabras. Hemos citado ya su alusión a una película de los hermanos Marx y no es un caso aislado, pues a lo largo de sus varios ensayos invoca otros títulos como Una proposición indecente (Indecent Proposal, Adrian Lyne, 1993), Inseparables (Dead Ringers, David Cronenberg, 1988) o Crash (Cronenberg, 1995), así como la novela homónima de J.G. Ballard que adapta esta última -a la que consagra un capítulo entero en su Cultura y simulacro- o acontecimientos mediáticos tales como la muerte de Diana de Gales, con la intención de coronar sus opiniones en torno a la imposibilidad de forzar el valor -y el canje comercial- de lo que no podemos poseer nosotros mismos-, la fascinación por el doble, la sincronía entre muerte, sexo y simulación, o el deseo del acontecimiento mediático como exorcismo eventual del miedo al exceso de significado.

\section{OBJETIVOS}

En las líneas que siguen, sin embargo, centraré el estudio en la imagen y en los efectos de sus multiplicaciones y transformaciones como elementos pilares en la articulación de la era de la hiperrealidad. Pero también, y quizá más importante, trataré las consecuencias que los cambios en sus condiciones de reproductibilidad técnica han propiciado en un contexto ineludiblemente capitalista y mutante. Transformaciones, sin duda, que toman como punto de referencia la pérdida del aura en la obra de arte predicada por Walter Benjamin en La obra de arte en la época de su reproductibilidad técnica, pero también su reflexión en torno a los agentes que intervienen en ese escenario cambiante de un consumo de imágenes cada vez a mayor velocidad: «La orientación de la realidad hacia las masas y de las masas hacia ella es un proceso de alcances ilimitados lo mismo para el pensar que para el mirar» (Benjamin, 2003, p. 48). En ese contexto, cercar la naturaleza actual de la imagen y sus repercusiones es, quizá, el único modo de saber si nos hallamos más cerca o más lejos de esa transparencia total de la que hablaba Baudrillard. De atisbar el futuro, siempre incierto, desde la profunda indeterminación de nuestro presente.

\section{DISCUSIÓN}

\subsection{Del espectáculo al simulacro}

Hemos hablado más arriba del estilo de El crimen perfecto, de su escritura casi abrupta y aparentemente instintiva pese a las hondas reflexiones que promueve. A este respecto, no andaría muy lejos de otro texto fundamental en el pensamiento del siglo XX: La sociedad del espectáculo (1967) del situacionista Guy Debord, con el que además se emparenta mediante una interesante relación de continuidad en cuanto a diagnóstico del mundo se refiere. Debord escribió su libro a base de aforismos más o menos contundentes, quizá consciente del impacto amplificador que tendría sobre su discurso. Pero lo verdaderamente fascinante es comprobar hoy cómo sus ideas ya señalaban el principio de un camino que habría de seguir años más tarde Baudrillard. La sociedad del espectáculo del primero es el estadio que precede a la era del simulacro del segundo. El mismo Baudrillard confirma ese vínculo cuando en El crimen perfecto afirma que «la virtualidad no es como el espectáculo, que seguía dejando sitio a una conciencia crítica y al desengaño. La abstracción del espectáculo, incluso para los situacionistas, jamás era inapelable, mientras que la realización 
incondicional lo es, pues nosotros ya no estamos alienados ni desposeídos, poseemos toda la información» (Baudrillard, 1995, p. 30). Por supuesto, la relación no es de analogía, pues mientras el espectáculo describe un cúmulo de relaciones entre un sistema -capitalismo- y el individuo -consumidor/productor-, el simulacro ya ha incorporado al individuo como actor consciente, por lo que la dualidad ya no es posible, ni válido el esquema comunicativo para una sociedad de masas. Sin embargo, sí les une el hecho de que la mediación de la imagen se revela indispensable para deconstruir el principio sistémico que la genera en cada caso. Y de hecho, se cristaliza en formas de representación concretas: en La sociedad del espectáculo, la imagen audiovisual es referenciada como articuladora de ese orden capitalista, ya sea a través de la televisión -la cual es mencionada explícitamente en el texto como uno de los aparatos espectaculares-o el cine -cuya referencia es más bien implícita-. No es casualidad que una de las imágenes más repetidas en las portadas de las diversas ediciones del libro de Debord sea precisamente la de la fotografía de J.R. Eyerman para la revista Life, aquella en la que vemos a un grupo de espectadores que asisten a la primera proyección de una película en 3D, Bwana Devil (Arch Oboler, 1952). Existe un componente irónico en ella, pues la fotografía de un grupo de gente en el cine con gafas 3D podría no ser tanto una imagen referente al espectáculo como una que ya insinúa el simulacro. El cine, en su concepción tradicional de acto colectivo tal y como lo pensaron los hermanos Lumière, era para Debord un medio espectacular en tanto que reproductor y difusor de un presunto discurso de lo real. La imagen cinematográfica, por tanto, sería para el consumidor esa ilusión de lo real sobre una pantalla, en la que podría proyectar sus sueños y deseos, pero nada más. En el momento el espectador se pone las gafas 3D, está accediendo -o cree acceder- a un grado mayor de realidad. Hay una fantasía de ruptura de los límites comunicativos del espectáculo cinematográfico y de penetración en este, que se traduce en una imagen en relieve que es la ilusión de inmersión y participación. Pero en realidad, ni el cine en 3D de la década de los 50 podía consumar esa participación total del espectador en el espectáculo ni el cine en general podía ser el medio espectacular por antonomasia, pues este debía ir asociado a un aislamiento que formara las muchedumbres solitarias (Debord, 1995, p. 11), y que se da de forma más evidente e intensa en el caso de la televisión. El cine, en cambio, podía ser herramienta de adoctrinamiento -el cine de propaganda, cualquier cine de ficción o no ficción en connivencia con el poder político y/o económico-, pero por sus condiciones de reproducción aún deja margen al diálogo e intercambio social, a una esfera de socialización en la que es posible el debate y la crítica. Con la televisión, el sistema espectacular daba un paso al frente hacia el aislamiento del individuo. Con el cine, todavía quedaba un resquicio para su reacción, resquicio que debía ser extirpado. Esto es lo que ha logrado el simulacro mediante la multiplicación de las pantallas y la híper profusión de la imagen: la posibilidad socializadora ha quedado eliminada en la expansión ad infinitum de una serie de dispositivos móviles que personalizan las condiciones de reproducción al gusto del usuario. El proceso comunicativo del medio cinematográfico queda así enteramente transformado, pues ya no depende de un contexto específico ni está sujeto a las reglas del mensaje unidireccional -la imposibilidad del receptor de detener y reanudar la película a su 
antojo-. Con la película contenida en un soporte portátil, el espectador pasa a ser usuario con plena capacidad de decisión y control sobre lo que ve. Ahora es el dueño del relato y puede consumirlo cómo y cuándo le plazca. En cuanto al acto comunal consustancial al cine en su forma tradicional de recepción, este no puede ser completamente erradicado, al menos no de momento. No obstante, sí puede ser reubicado, reconvertido según los intereses de la era del simulacro. Antes los palace cinemas reunían a más de mil personas frente a una única (y enorme) pantalla. Los estrenos disfrutaban de una calidad de gran acontecimiento, de evento irrepetible que incluso podía arremolinar al star-system para la ocasión. La evolución de la televisión obligaría con el paso de los años a una readaptación a salas más modestas. Con todo, hasta bien entrados los 90 un espectador podía elegir en una ciudad como Valencia entre una docena de salas situadas en el casco urbano: seguía siendo posible la experiencia del cine sin necesidad de que esta estuviera supeditada a otro tipo de continente, a otro tipo de experiencia. Evidentemente, esto cambió con la llegada de los multiplex y su integración en centros comerciales. De repente, los cines se vieron expulsados fuera de las ciudades y pueblos, reubicados en complejos de alturas y dimensiones varias en los que compartían espacio con todo tipo de tiendas y actividades de ocio. De esta manera, el cine dejó de ser una experiencia que ponía en itinerancia a sus espectadores, las antiguas salas del área urbana cerraron y los nuevos multisalas, propiedad de multinacionales y majors de Hollywood, se convirtieron un suplemento más para familias y parejas embarcadas en intensas jornadas de vertiginoso consumismo en el extrarradio. Ya solo era -y ha sido hasta hoy- otra parte más en lo que Baudrillard vino a definir como «el modelo de toda forma futura de socialización controlada en un espacio-tiempo homogéneo del cuerpo y de la vida (trabajo, ocio, alimentación, higiene, transporte, medios, cultura) $\gg^{4}$.

\subsection{El estatus de la imagen o la progresiva dilución del referente}

En ese contexto, ¿qué valor puede quedar en la imagen? No solo se ha devaluado la experiencia de ir al cine: la misma imagen audiovisual ha perdido todo su valor como discurso en favor de la profusión y la dispersión. Ya no es el centro de una ceremonia que mucho tenía de religiosa, y por supuesto hace tiempo que perdió el aura benjaminiana. Destruida su jerarquía, la imagen deja de ser única para ser múltiple, deja de ser sagrada para ser rizomática, ya no es (supuestamente) el reflejo de una realidad, sino solo el reflejo de la realidad que valida en sí misma. Toda ceremonia a su alrededor que le confiriera un cierto halo mítico ha sido suprimida, por lo que ya solo vive de las apariencias, una vulgar máscara que apenas puede encubrir el vacío

\footnotetext{
${ }^{4}$ «L'hypermarché est déjà, au-delà de l'usine et des institutions traditionnelles du capital, le modèle de toute forme future de socialisation contrôlée : retotalisation en un espace-temps homogène de toutes les fonctions dispersées du corps et de la vie sociale (travail, loisir, nourriture, hygiène, transports, media, culture)» / «El hipermercado es ya, además de la fábrica y de las instituciones tradicionales del capital, el modelo de toda forma futura de socialización controlada en un espacio-tiempo homogéneo del cuerpo y de la vida (trabajo, ocio, alimentación, higiene, transporte, medios, cultura)» (Baudrillard, 1981, p. 115).
} 
que subyace. Recordemos cuáles serían las fases sucesivas de la imagen para Baudrillard:

- La imagen como reflejo de una realidad profunda.

- La imagen enmascara y desnaturaliza una realidad profunda.

- La imagen enmascara la ausencia de realidad profunda.

- La imagen sin relación alguna con cualquier realidad, como su propio y puro simulacro.

En el primer caso es una buena apariencia y su representación pertenece al orden del sacramento. En el segundo, es una mala apariencia y se equivale al orden del maleficio. En el tercero, juega a ser una apariencia y ya entraría en el orden del sortilegio. Por último, en el cuarto no pertenecería ya al orden de la apariencia, sino al de la simulación ${ }^{5}$. Efectivamente, en el paso del espectáculo al simulacro la imagen ha perdido su sólida apariencia de lo real y ha quedado desvinculada de esa relación directa. De hecho, ha perdido su referente para constituirse ella misma como su propia referencia, en una autonomía simulada que es síntoma de la virtualidad en la que se halla sumido el mundo. Tras el ataque a las Torres Gemelas del 11 de septiembre de 2001, algunos informativos televisivos emitieron imágenes en las que se podía ver a los habitantes de un poblado islámico supuestamente celebrando el éxito del acto terrorista. No pasó mucho tiempo antes de que se descubriera que se trataba de imágenes de archivo que nada tenían que ver con el ataque al World Trade Center. La superposición de sentido habla de la vaporosidad de las imágenes ya desgajadas de su referente: estas pueden significar lo que queramos y cuando queramos, pues detrás de ellas solo hay vacío. Ya no existe el imperativo del significado original, ya que el contexto es altamente maleable a expensas del interés personal. Resulta curioso que Debord luchara contra la tiranía del sentido fijado, del signo unívoco, una batalla que hoy ya sería inútil. Para él, una crítica del sistema espectacular solo era pronunciada globalmente y contra todos los aspectos de la vida social alienada (Debord, 1995, p. 49). Cabe pensar que dentro de esos aspectos se hallaba la imagen presta a ramificar la ideología del espectáculo, por lo que la única manera de combatir dicha servidumbre era precisamente mediante la ruptura del lenguaje con sus referentes de lo real. En 1951, Debord había asistido al Festival de Cannes y había comprobado las posibilidades del medio en la proyección de Traité de bave et d'éternité (1951), de Isidore Isou. Unos años más tarde, él mismo realizaría La société du spectacle (1973), largometraje que llevaba el título de su obra más importante y que tomaba como principio el concepto de $\operatorname{desví}^{6}$, forjado en la pantalla a través de

\footnotetext{
5 Telles seraient les phases successives de l'image:

- elle est le reflet d'une réalité profonde

- elle masque et dénature une réalité profonde

- elle masque l'absence de réalité profonde

- elle est sans rapport à quelque réalité que ce soit : elle est son propre simulacre pur.

Dans le premier cas, l'image est une bonne apparence - la représentation est de l'ordre du sacrement.

Dans le second, elle est une mauvaise apparence - de l'ordre du maléfice. Dans le troisième, elle joue à

être une apparence - elle est de l'ordre du sortilège. Dans le quatrième, elle n'est plus du tout de

l'ordre de l'apparence, mais de la simulation (Baudrillard, 1981, p. 17).

${ }^{6}$ El origen del concepto desvío (détournement) se remonta a los años de Debord en la Internacional

Letrista. En el número 8 de Les Lèvres Nues, publicado en mayo de 1956, Debord y Gil J. Wolman
} 
la reutilización de imágenes ya existentes sacadas de su contexto -la película incluía material de archivo de George Harrison, Johnny Hallyday, Adolf Hitler, Henry Kissinger o Fidel Castro, entre otros- y, por tanto, despojándolas de su condición de cita. En la actualidad, de poco serviría ya la empresa de Debord, puesto que la imagen ya ha perdido su referente y solo pervive en su propio simulacro: ya no hay en ella margen para lo real. A este respecto, la sentencia más convincente la firmaba Baudrillard en El crimen perfecto:

«La imagen ya no puede imaginar lo real, ya que ella misma lo es. Ya no puede soñarlo, ya que ella es su realidad virtual. Es como si las cosas hubieran engullido su espejo y se hubieran convertido en transparentes para sí mismas, enteramente presentes para sí mismas, a plena luz, en tiempo real, en una transcripción despiadada. En lugar de estar ausentes de sí mismas en la ilusión, se ven obligadas a inscribirse en los millares de pantallas de cuyo horizonte no sólo ha desaparecido lo real, sino también la imagen. La realidad ha sido expulsada de la realidad» (Baudrillard, 1995, p. 11)

Aquí podríamos invocar la dimensión de la imagen en tanto que signo y parte de un lenguaje: la pérdida de fuerza del signo es el indicador de la creciente volatilidad del lenguaje. En Seis propuestas para el próximo milenio, Italo Calvino aseguraba tener la impresión de ser testigo de una epidemia que azotaba la humanidad en aquello que más le caracterizaba: el uso de la palabra. El escritor y periodista italiano la tildaba de «una peste del lenguaje que se manifiesta como pérdida de fuerza cognoscitiva y de inmediatez, como automatismo que tiende a nivelar la expresión en sus formas más genéricas, anónimas, abstractas, a diluir los significados, a limar las puntas expresivas» (Calvino 1995, p. 72). Algo muy similar ocurre con la imagen, limada de significado y convertida en signo anulado en lo genérico. Sin embargo, sí existe aún la posibilidad de la ruptura, el engaño al simulacro y la violación de esa virtualidad. Existe al menos en alguna medida, de manera intrínseca en algunas imágenes. En I'm dreaming of a Black Christmas (1971), el artista pop británico Richard Hamilton tomaba un fotograma del largometraje Navidades Blancas (White Christmas, Michael Curtiz, 1954) y lo convertía en imagen en negativo. El resultado tenía claras implicaciones ideológicas: su protagonista Bing Crosby, figura asociada a una tradición familiar conservadora y cristiana vería su color de piel invertido al negro. El óleo se torna así incómoda igualación racial, eterno comentario de la imagen original y de los valores inherentes al personaje. Por más que esta sea objeto de miles de reproducciones y copias, en teoría todas ellas debían se ven obligadas a dialogar de nuevo con su referente primigenio. Dejando a un lado el aspecto ideológico, la recontextualización mediante la técnica es también primordial en otra obra de Hamilton, Trafalgar Square. En este caso la intencionalidad descansa en la innovación artística: una fotografía de la famosa plaza londinense, un zoom aplicado sobre una parte de la imagen hasta distorsionar las figuras que habitan en ella y la pintura que reinventa la imagen sobre esa porción difuminada de realidad -o mejor dicho, su reproducción-. El resultado perdería toda vinculación con el contexto original si no fuera porque Hamilton opta

firmaban «Mode d'emploi du détournement», en el que detallaban en qué consistía el uso de dicho concepto (Debord y Wolman, 1956). 
por mantener el referente en el título de la obra. No vemos que es Trafalgar Square, pero sabemos que es Trafalgar Square porque el artista nos obliga, desde el paratexto, a observar el mismo lugar desde otro punto de vista: ¿Qué mejor manera de reconquistar una realidad que de otra forma nos sería ya vulgar? Ambas obras de Hamilton ofrecen una gran resistencia frente a la erosión de la transparencia del simulacro, y aun así son en cierto modo susceptibles de ser absorbidas por este. Crosby puede ser un referente diluido en generaciones venideras de consumidores de imágenes, y esa reelaboración pictórica sobre una parte de Trafalgar Square puede multiplicarse meramente como abstracción. El único atributo que les puede liberar definitivamente es el de su mercantilización, una consciencia de objeto-mercancía que sí que encontramos en Andy Warhol. Para el francés todo en Warhol es ficticio, «el objeto es ficticio, porque ya no tiene relación con el sujeto, sino con el mero deseo de objeto» (Baudrillard, 1995, p. 73). Desprendido de su significación natural, ya es objeto-fetiche y por tanto artificio. Al igual que las obras de Hamilton, suprime el imaginario original de la imagen, solo que aquí lo hace para otorgarle el valor de la mercancía. Así, la imagen-mercancía warholiana solo se entiende despojada del deseo trascendente y la estética, su esencia es la de la pura inmanencia, valor superficial y a la vez absoluto del deseo consumista. Baudrillard alinea esa intención con la radicalización del arte propuesta por Charles Baudelaire, quien quería convertirlo en mercancía absoluta. Solo así la imagen puede escapar a la estetización de la imagen, proceso que la aboca al simulacro, o a la expresión sentimental y burguesa de la publicidad7. Es decir, Baudelaire defiende una objetivización absoluta que para Baudrillard se traduciría en el arte abundando «en el sentido de la abstracción formal y fetichizada de la mercancía, de una suerte de valor de cambio feérico, y volverse más mercancía que la mercancía ir pues más lejos aún en lo que respecta al valor de cambio y así escapar de él radicalizándolo» (Baudrillard, 2006, p. 21). Para ello, el arte de Warhol se fundamenta sobre la necesidad de volverse una máquina absoluta, de apuntar a «la reproducción automática, maquinal, de objetos ya mecánicos, ya fabricados, así sea una lata de sopa o el rostro de una star» (Baudrillard, 2006, 22).

\subsection{Una nueva religión}

Así pues, solo (una parte de) el arte pop en su rebelión y consciencia podría sobrevivir a la progresiva disolución del referente a manos del simulacro, y prácticamente nada sobrevive ya a la expulsión del texto artístico del centro del discurso. Sin embargo, y aunque el simulacro se base en la profusión y la promiscua reproducción, sigue siendo preciso un discurso vertebrador que pueda conservar el status quo de las cosas. La evolución hacia la transparencia total no es sostenible sin una jerarquía de lo real, sin un equivalente al orden religioso que primaba en el espectáculo. Cuando ya acaricia su perfección total, en la que no ha de encontrar impurezas ni resistencia, el simulacro requiere una alternativa para mantener intacto

\footnotetext{
${ }^{7}$ Baudrillard desarrolla este vínculo entre Warhol y Baudelaire en sus conferencias dictadas en el Centro Documental de la Sala Mendoza durante su estancia en Caracas en 1994. Estas se hallan recogidas en El complot del arte: ilusión y desilusión estéticos (Baudrillard, 2006).
} 
su espejismo. Desplazada la imagen y la instrumentalización del sentido a un segundo o incluso tercer plano, es el soporte el que pasa a ocupar el lugar central. Es una decisión sumamente astuta, pues mientras las imágenes escapaban a su control total, el soporte se atiene a su dominio sin resquicios. De esta manera, la profusión pornográfica y ya vaciada o de sentido manipulable de las imágenes puede continuar, en tanto que son los dispositivos que la propician la verdadera estrella. Las últimas innovaciones tecnológicas en teléfonos móviles de última generación, tablets y ordenadores portátiles acaparan ya la atención en detrimento de la imagen como texto, por lo que ya no importa su carácter de mediación cultural ni sirve como catalizador por la reflexión. Es la tecnología la que ha ocupado el lugar del fetiche/mercancía, y frente a eso la imagen poco puede hacer. En ese nuevo contexto, se ve obligada a diluirse en la multitarea, a conformarse con ser un mero icono en una interminable lista de posibilidades que permiten organizar nuestras necesidades de evasión, de consumir, de organizar nuestros asuntos laborales, de gestionar nuestro tiempo de vida ${ }^{8}$. Todas nuestras funciones vitales y las respuestas a nuestros deseos comprimidas elegantemente en un pequeño soporte que podemos sostener en nuestras manos, versión a pequeña escala -aunque, paradójicamente, con opciones menos reducidas gracias a lo ilimitado del entorno digital- de los centros comerciales como modelos de control sobre las formas de producción y socialización. Toda la vida al alcance en una pantalla táctil, solo que el individuo ha olvidado ya que no se trata de la vida, sino de su impecable simulación. Se consuma así el paso de las tecnologías modernas como extensiones del hombre, tal y como las entendía Marshall MacLuhan, a las tecnologías modernas como expulsiones del hombre, como afirmaba Baudrillard (Baudrillard, 1995, p. 38).

Ese ascenso de lo tecnológico de mediación a fin ha ocurrido en parte gracias a una impresionante estrategia de auto-legitimación. En la competencia entre las empresas tecnológicas más poderosas del mercado, triunfa una suerte de diferenciación que se asemeja tanto a una nueva fe como a un sofisticado club que se identifica como la élite en este tipo de productos. Su mensaje parece decir: «mi producto es mejor que el de mi competidor y por eso debe pagar un precio más alto, pero a cambio recibirá la garantía de que no hallará problemas y podrá entrar en nuestro exclusivo club, el único que cuida de los suyos y atiende perfectamente a sus necesidades». Y este se articula a través de una impoluta imagen de marca identificada en la pureza de los tonos blancos y la sencillez de sus iconos, que son los nexos unificadores para los devotos de ese nuevo credo. Estos funcionan del mismo modo que la iconografía de

\footnotetext{
${ }^{8}$ En este punto, cabe recordar los argumentos esgrimidos por Baudrillard en La sociedad de consumo en torno al valor del tiempo en el capitalismo: «... asistimos a una imposibilidad lógica del tiempo libre: sólo puede haber tiempo obligado. El tiempo del consumo es el de la producción. Lo es en la medida en que nunca constituye más que un paréntesis evasivo en el ciclo de la producción (...) El ocio está constreñido en la medida en que, detrás de su gratuidad aparente, reproduce todas las restricciones mentales y prácticas propias del tiempo productivo y de la cotidianeidad sometida (...) la totalidad y la espontaneidad que quiere devolvernos el ocio, por darse en un tiempo social marcado esencialmente por la división moderna del trabajo, adquieren la forma objetiva de la evasión y la irresponsabilidad. Ahora bien, esa irresponsabilidad del ocio es homóloga y estructuralmente complementaria de la irresponsabilidad en el trabajo. La libertad por un lado y la obligación, por el otro: la estructura es la misma (Baudrillard, 2009, p. 193).
} 
una religión, e incluso vienen acompañados de la exaltación de su figura creadora, santificada como genio inventor y benefactor de la humanidad. En el otro lado, los resultados del adoctrinamiento son sorprendentes y presentan réplicas de las expresiones más radicales de algunas de las religiones oficiales: el usuario hará largas colas e incluso pedirá el día libre en su trabajo para tener la posibilidad, antes que nadie, de tener en su poder la última versión que sale a la venta de un teléfono móvil o tablet, a un precio cada vez mayor que llegará cuando apenas haya acabado de pagar los plazos de su anterior versión. También, increpará a todo aquel que se atreva a cuestionar la lógica de esa religión tecnológica y no tardará en recurrir, a menudo con vehemencia, al argumento de la calidad de los productos y la incuestionable superioridad sobre aquellos de la competencia. Surge así una forma de integrismo sin violencia que es la mejor herramienta para garantizar la continuidad y crecimiento de esa fe ciega y consumista. El éxito reside en el grado de convicción y creencia insuflado en los seguidores, quienes serán los mejores portadores del discurso oficial que sostiene otra victoria del simulacro. Pero aún hay margen para un triunfo mayor, el cual ya está alcanzando y se equiparará a la transparencia ineluctable del simulacro: un estadio en el que el consumidor es incluso consciente de esa lógica comercial salvaje de productos que nacen con su fecha de caducidad ya programada, pese a lo cual seguirá abrazando su fe consumista. Es decir, que el individuo ya no es solo actor de la performance, sino que además sabe ya de las condiciones bajo las que la ejecuta. El grado de refinamiento dentro del concepto de simulacro es asombroso, pues ese individuo ha accedido a una nueva fase en la que, conociendo la lógica del sistema en que participa, podría volverse contra ella, pero prefiere aceptarla y seguir alimentándola. Nada importan ya cuestiones como la funcionalidad, la innovación o las promesas de mejoras, pues la promesa que impera es la del fetiche tecnológico adscrito a la brevedad, a la evanescencia que precede a su actualización. Ya no hay posibilidad de rebelión, pues el grado de transparencia es tal que su comprador está de acuerdo en adquirir algo que tiene su obsolescencia asegurada. Cuando ha aceptado seguir siendo miembro de ese club incluso a sabiendas de esa información, nada queda ya por hacer, puesto que ha comprometido su búsqueda de la felicidad (consumista) al reino eternamente insatisfecho de la expectativa. Y esa auto-consciencia es la que marca el triunfo último del simulacro en su forma más perfecta: aquella en la que el individuo se sabe doblegado por un sistema pernicioso para sus intereses, pero que acepta a cambio de una concretizada búsqueda de la felicidad que nunca culminará. Es también el triunfo de la sociedad de consumo. En el episodio Comisiones y honorarios (Commissions and Fees, \#12x05, Christopher Manley: 2012) de la serie Mad Men (Matthew Weiner, AMC: 2007-2015), su protagonista Don Draper (Jon Hamm) se encargaba de ponerlo en palabras: «Happiness is a moment before you need more happiness ${ }^{9}$. Solo queda sustituir la palabra happiness por cualquiera de esos multifuncionales, deseados y rápidamente obsoletos objetos efímeros.

\footnotetext{
${ }^{9}$ «La felicidad es el momento anterior al momento en que necesitas más felicidad».
} 


\subsection{La desaparición del arte}

Ese ascenso y exaltación del fetiche tecnológico ha reemplazado la necesidad de un texto, ha expulsado al contenido del continente. Por tanto, la cultura en sus diversas facetas artísticas deja de tener relevancia: esta se halla más alcance que nunca, en una infinidad de opciones, pero se encuentra defenestrada bajo la premura y carácter efímero de lo real -o mejor dicho, la virtualidad de lo real-. Todo queda subordinado a la fe en la doctrina evangélico-tecnológica. No hay nada que no pase por el filtro de lo virtual, del reflejo que se desvanece. Hoy, el discurso religioso-tecnológico tiene el poder que antaño disfrutaron el político o el católico, los cuales han perdido terreno. En este nuevo paradigma, se producen paradojas de lo más desconcertantes que afectan a las distintas expresiones artísticas. Por ejemplo, tras más de un siglo de transformaciones, el cine vuelve a su etapa primigenia, acuñada por Tom Gunning como cine de atracciones. Ha dejado de ser el acto comunal ideado por los Lumière para volver a ser un acto individual como lo ideó Edison. Es decir, la idea colectiva del cine es sustituida por el cine como pasajera evasión en los barracones de feria de finales del siglo XIX. La diferencia es que ya no está circunscrito a ese contexto de exhibición, sino que puede ser consumido en cualquier lugar y condiciones. En ese marco, el dispositivo móvil hoy reemplaza al zoetropo o al kinetoscopio de ayer. La fascinación por lo tecnológico vuelve a ser la razón de ser del invento, y no las posibilidades expresivas que surgen de él. La prueba de que la imagen ya no es relevante es la alta definición, la cual aplica una tabula rasa: la imagen solo será valiosa en tanto que su calidad, y aquí sería pertinente recordar la máxima baudrillariana que reza que «la más alta definición del medio corresponde a la más baja definición del mensaje» (Baudrillard, 1995, p. 32) ¿Y cuál es el baremo para medir esa calidad? Que esa imagen se asemeje lo más posible a lo que entendemos por realidad, que despliegue en su textura digital las reproducciones más fieles del mundo que percibimos y en que vivimos en nuestras experiencias del día a día. Poco importan las intenciones artísticas en el uso del color que en su origen definieran la obra en sí, así como la elección del formato de reproducción o el material en que fue filmado. Su destino último es el de la pantalla de plasma HD que limará esas impurezas y la convertirá en la expresión de la hiperrealidad: «Nada que ver con la representación, y menos aún con la ilusión estética. Toda ilusión genérica de la imagen es aniquilada por la perfección técnica» (Baudrillard, 1995: 33). Esa identificación de lo real en la pureza del tejido pixel podría desembocar en el hipotético caso de un espectador en su sofá que contempla en la pantalla una ficción en la que se muestra un espectador en su sofá mirando el televisor. Si la imagen ya ha perdido todos sus valores estéticos a favor de la definición más próxima al ojo humano, ¿acaso ese televidente no estaría ya asistiendo a su propio reflejo? La pantalla convertida en espejo, victoria definitiva del simulacro. La prueba más evidente se halla en el éxito de los incontables programas de reality show que replican el modelo Big Brother (John de Mol, Veronica: 1999- ): audiencias desorbitadas para un simulacro de la vida cotidiana o su versión dramatizada, a menudo indistinguibles la una de la otra. El espectador tanto se sienta fascinado en el sofá a contemplar los conflictos espectacularizados entre los participantes, destacados como grandes momentos del programa en las galas -el espectáculo subrayado- como 
recurre al directo transmitido durante 24 horas por las cámaras que se hallan en el interior de la casa/plató. En el primer caso, está asistiendo a un reflejo aumentado, deformado por la dramatización banal. En el segundo, se encuentra frente a su propio reflejo, banal pero no dramático, en teoría sin mediación alguna. El problema es, también, que ese espectador ya no puede estar seguro de si la imagen sigue teniendo ese carácter mediado, si su misma naturaleza no lo ha absorbido ya y con él a la perversa lógica orwelliana detrás del título. En una escena de El show de Truman (The Truman Show, Peter Weir, 1998), el protagonista encarnado por Jim Carrey se sitúa frente al espejo de su baño y lo mira fijamente. Al otro lado están los espectadores asistiendo a su día a día sin que -aparentemente- él sea consciente de ello. Sin embargo, en secuencias anteriores el personaje a punto ha estado de descubrir que su población, Seaheaven, no es más que un gigantesco plató de televisión y que su vida es el centro de atención de un reality de enorme éxito en todo el mundo. Por esta razón, cuando llega la escena descrita, el espectador del film tiene la duda de si Truman sabe o no lo que realmente está pasando. Su mirada fija y perdida en el espejo durante varios segundos alerta a dos técnicos del programa, que llegan a pensar que efectivamente ha descubierto la verdad. Acto seguido, empero, Truman comienza a jugar con el jabón sobre el espejo y a imitar a un astronauta, devolviendo la calma a los técnicos. Luego, Truman borra el dibujo realizado con una toalla, guiña un ojo a la cámara/espejo y dice: «That one's for free» ${ }^{10}$. Aunque aparentemente no tiene una incidencia importante sobre el relato, la secuencia propone un doble juego que se asemeja extraordinariamente a la situación que vivimos en el simulacro: todos somos actores y espectadores en la impecable simulación del mundo, y ya ni siquiera podemos estar seguros de la imagen que nos devuelve el espejo.

¿Y qué decir de la fotografía o la pintura? Por supuesto, estas ya se hallan desgajadas de sus contextos y condiciones de producción. Son imágenes sin aura, sin historia ni más futuro que el de perpetuarse en copias infinitas que no respetan necesariamente el formato o el color. Todas son imágenes que flotan en bancos de imágenes, sin un espacio de exposición que las contextualice. Desde luego, podemos encontrar el apunte wikipédico, la información enciclopédica y aledaña. Pero ni siquiera tendremos la certeza de que dicha información sea fiable, pues el simulacro ha permitido que cualquiera de sus actores se halle capacitado para proporcionarla al resto. Como dice Harold Bloom, «en Internet está todo el conocimiento, pero falta la sabiduría» (Bloom, 2002, p. 13). Allí, las imágenes pululan a una velocidad frenética, como si de desordenadas partículas de lo digital se tratase. El valor estético, la jerarquía y el orden de los gestos artísticos quedan ya restringidos al espacio museístico, que en esencia deja de ser un espacio de difusión cultural para serlo de elitismo cultural. Entretanto, la red alberga la última manifestación de una imagen vaciada que ansía recobrar su identidad: el selfie. Miles, millones de personas anónimas que repiten a diario auto-fotos hechas con su móvil en relación con distintos contextos. Hay implícita en esa moda una necesidad por mantenernos visibles, por seguir constatando que existimos en la virtualidad infinita del mundo. Por eso el contexto es solo importante en la medida en que el selfie relaciona a su

\footnotetext{
10 «Esta ha sido gratis».
} 
protagonista con él, en tanto que explicita que sí existe una relación con lo real. Al contrario que los miembros de algunas antiguas sociedades que evitaban hacerse fotografías por miedo a perder el alma, el selfie insiste en recuperarla por la vía de la insistencia y la profusión. Es como en el episodio The Time of Angels (\#04x05, Adam Smith, 2010) de Doctor Who (Sydney Newman, C. E. Webber y Donald Wilson, BBC: 2005- ): en un momento dado, el Doctor (Matt Smith) y sus compañeros de aventura descubren que los ángeles llorones que amenazan su vida en un gigantesco laberinto han perdido su imagen y con ella su fuerza, su vitalidad. La imagen ya no es el suplemento, sino la garantía de la identidad. El selfie es, por tanto, una carrera contra la dilución del yo que ejerce el simulacro, a la vez que su propia reafirmación. Es una patología que surge consecuentemente de la realidad simulada y que reproduce fotografías idénticas las unas respecto a las otras, con el único fin de registrar el paso del tiempo y empeñarnos en atestiguar nuestra presencia en el aquí y ahora. Y de nuevo, encontramos a nuestra disposición las herramientas que reafirman la autosuficiencia del acto sustitutivo de la experiencia: los brazos extensibles que permiten realizar la instantánea enmarcándonos en el entorno, sin la necesidad de que otro intervenga. Solo nosotros en relación con un contexto y un tiempo que desaparece inmediatamente. La foto sustituida por el acto de la foto. La participación del fotógrafo ajeno a nuestra individualidad, eliminada de la ecuación.

También la música se separa en un grado cada vez más virtual de su interpretación primera, dado que ya ni siquiera un concierto en directo es garantía de lo real: son las industrias discográficas las que deciden hasta dónde alcanza la dictadura del playback, además de quién puede acceder a ella y cómo apelará a su público. Todo está medido, previsto, desde la coreografía hasta el tipo de sonido, todo planificado dentro de una lógica cada vez más vertiginosa de acceso a la fama y desaparición, como un gigantesco aparato de mercadotecnia que renueva ídolos a un ritmo que apenas deja margen a su asimilación. No es la explosión efervescente del punk, que se erigía como reacción visceral al todo: lo efímero del fenómeno punk es el equivalente a una explosión que atenta contra la inopia social, una llamada a la revolución que rompe con las normas de la industria musical desde los sonidos violentos y desordenados y las actuaciones sumidas en el caos y lo imprevisible. Por decirlo con Greil Marcus (Marcus, 2011), un movimiento así solo podía existir, al menos en su forma más honesta, como un relámpago o una sacudida furiosa antes de ser absorbido por el espejo del simulacro. Y efectivamente, eso fue lo que sucedió. En la actualidad, cualquier rastro de aquel estado de excepción ha quedado ya fagocitado por el sistema y reconvertido en producto también efímero, pero en el que el sentido de lo único ha quedado ya destrozado, por ejemplo con la profusión obscena del videoclip montado, remontado y reproducido ad infinitum. A este respecto, ya no hay distinciones entre lo real del escenario y la ficción del videoclip, pues en ambos casos hablamos de simulación total que garantiza los 15 minutos de gloria a los elegidos que la abracen.

Por otro lado, la literatura no presenta un horizonte más halagüeño. Tenemos la opción de acceder a bibliotecas ilimitadas solo con apoyar el dedo en una pantalla táctil, sin embargo es espacio para la literatura queda sepultado por lo virtual, subordinado a una infinidad de posibilidades multimedia. Pero todas ellas se 
presentan en igualdad de condiciones, pues en principio no hay unas opciones destacadas sobre otras. ¿Por qué habríamos de pensar entonces que se ha producido una subordinación? Porque en la aglomeración de actividades relacionadas con el ocio y trabajo en nuestra pantalla la literatura es solo un apartado insignificante, y porque sus condiciones de consumo ya no pueden ser las mismas. El ejercicio de lectura de un libro de papel requería una dedicación exclusiva que ya no precisa su versión en digital. Pero más importante aún, la reubicación de la literatura en ese entorno virtual viene marcado por un factor determinante: el ritmo de consumo y la dispersión inculcados por el simulacro y enfatizado por la ansiedad frente al mosaico de aplicaciones difiere notablemente de aquel que exige la literatura en su forma anterior de consumo. El tradicional orden editorial y la cadena de producción literaria quedan, en esencia, obsoletos: lo digital primará la auto-edición y hará una tarea casi imposible la criba del talento entre miles de textos flotando en la galaxia Internet. La apariencia de libertad absoluta para acceder al público no puede engañarnos, pues esta es en esencia irreal. Eliminadas las jerarquías editoriales, el respeto religioso que antaño se le tenía a la obra desaparece con ellas. Y con ellas desaparece también el respeto hacia el viejo y noble arte de la traducción, pues en el maremagno digital ha perdido su papel primordial en la transmisión de conocimiento frente al imperativo de la inmediatez. En los meses previos a la publicación de uno de los volúmenes de la saga Harry Potter, numerosos fans no pudieron soportar la espera y se movilizaron para poner en marcha traducciones no autorizadas destinadas a saciar el hambre de los seguidores. Poco importaban las condiciones en las que estas hubieran sido hechas, o cuántas manos hubieran intervenido en ellas, pues la calidad de la traducción era lo de menos. De hecho, la obra en sí era lo de menos, pues lo que importaba era la imagen de la obra, la promesa o expectativa que la antecedía, lo cual puede ser visto como uno de los efectos más directos del simulacro en su proximidad a la transparencia total.

En cuanto a expresiones artísticas como la ópera o la danza, en un principio estas ofrecerían desde su naturaleza una mayor resistencia al avance del simulacro. Sin embargo, los caminos de este son inescrutables y la experiencia en directo de ambas ya encuentra su reemplazo de saldo en las proyecciones de representaciones en grandes teatros y óperas del mundo en salas de cine. Se trata de un nuevo reflejo simulador que se canaliza a través de una realización televisiva, por supuesto diferente de la experiencia en directo, la cual es tratada como un evento deportivo en el que la cámara selecciona las interpretaciones o las emociones que merecen ser resaltadas en cada momento. La misma noción de espectáculo, la falsa equiparación de la experiencia, que se ofrece como la posibilidad de estar en el Bolshoi, el Mariinsky o la Metropolitan Opera en una sala, y en Wembley o Maracaná en la otra. Los multisalas ya no representan solo la reconducción de la imagen cinematográfica, sino que se tornan distribuidores de la virtualidad del mundo. Llegados a este punto cabría preguntarse, ¿hay alguna forma artística que escape a esa conversión que torna lo que conocimos como mundo real en su propia versión espectral? Quizá solo sea posible en artes como la escultura y el cómic. La primera porque cuenta con el beneficio de la corporeidad, quizá el último bastión frente a esa progresiva espectralidad. El segundo porque crea su propia referencialidad de manera intrínseca 
en su lenguaje: su forma y su contenido son la misma cosa, y su secuencialidad impide hablar de la pérdida de aura o de referente que se produce en las imágenes unitarias. El cómic crea su texto, su contexto e incluso su propio paratexto -obras como Watchmen, de Alan Moore y Dave Gibbons, son a la vez su propio comentario y su propio work in progress-, por lo que escapa a la posibilidad de su simulación y se rebela ante el vaciamiento mediante la autosuficiencia y particularidad de su propio lenguaje.

\section{CONCLUSIONES}

\subsection{Después del crimen perfecto}

La huella invisible del simulacro no solo elimina la esencia de la expresión artística. En sí, toda la cultura que se entienda como una mediación con el mundo camina hacia la indeterminación. Las acciones que nos definen en el día a día como seres humanos en relación a ese escenario que comprende nuestras vidas son cada vez más etéreas o están siendo reemplazadas gradualmente por la inteligencia programada y la técnica: cocinar, conducir, aprender... todo tiene ya su propia sustitución virtual, pues los robots de cocina cocinan por nosotros, los coches aparcan solos y el aprendizaje se desarrolla cada vez más en la esfera digital, en la que obtenemos la promesa de lo directo y lo flexible, sin la tradicional mediación de la transmisión oral. El caso de la educación es especialmente grave, pues esta, pilar fundamental en la configuración del futuro, ya no disfruta de las mismas bases para proseguir en condiciones óptimas su misión de legar el conocimiento, al mismo tiempo que es víctima de una fatídica capitalización: el conocimiento ya solo es útil si viene acompañado de un cierto sentido de la practicidad, si está asociado a la idea de ciencia en el sentido popperiano o si puede llevar a inmediatos réditos en una carrera de éxito. Materias como la historia o la filosofía pierden su valor porque sus beneficios no son inmediatos en la sabiduría del individuo. Su aplicación directa en el día a día del individuo no se corresponde con una producción económica que pueda encajar en la maquinaria capitalista. En definitiva, el simulacro ya se esfuerza por conquistar el mismo corazón de la sociedad, allí donde esta podía diseñar sus aspiraciones y apuntar a un horizonte de logros. El golpe último incidirá en su capacidad para gestionar la inopia de las masas en los distintos frentes cotidianos y también desde su misma formación. La pérdida de corporeidad es irreversible. La pérdida de la imaginación, insalvable.

Así pues, debemos volver a la pregunta que motiva este ensayo, ¿qué queda después del crimen perfecto? Y la respuesta sería que nada, pues esté habrá borrado sus huellas una vez haya consumado su perfección. En su perfección, sus efectos serán ya irreconocibles y no habrá ningún diagnóstico que realizar, pues la consciencia de un estado anterior de las cosas, de una noción primigenia de lo real ya no existirá. Cuando la huella haya sido completamente borrada y no quede ya imperfección alguna, solo entonces habrá un después del crimen perfecto, el cual será indetectable. Por eso es imposible ver más allá de esa frontera ilimitada en la que la consciencia desaparece: Baudrillard ya preveía en su propuesta unas consecuencias últimas que se prolongaban hacia el infinito incluso cuando ya solo quedamos nosotros mismos frente al espejo. La mejor ilustración sigue siendo la escena de las incubadoras en 
Matrix (The Matrix, Andy y Larry Wachowski, 1999), que Slavoj Žižek toma como ejemplo en Bienvenidos al desierto de lo real (Žižek, 2005). Los individuos de ese oscuro mundo dominado por las máquinas viven dormidos en cápsulas, envueltos en líquido placentario durante su sueño de lo que entienden por realidad. La secuencia nos da la clave también en cuanto al papel de la cultura en la era del simulacro: necesitamos que esta siga teniendo un rol protagonista como elemento mediador en nuestra relación con el mundo. La alternativa es nuestra expulsión del mismo, o mejor dicho nuestra auto-expulsión por la vía de la técnica y lo virtual. Seguir exaltando sin sospecha ni resistencia los avances agigantados de la tecnología en su supuesta intención de hacer nuestra vida más fácil supone ceder pulgada a pulgada nuestra esencia como seres experienciales. Supone, también, redefinirnos en nuestra naturaleza en tanto que modificamos nuestra noción de la experiencia para desdeñar lo sensible, lo corpóreo, por su réplica virtual. Un reciente anuncio de Google Glass ensalzaba la idea de la experiencia compartida a través de los ojos de otra persona. Es el enmascaramiento definitivo, pues sugiere que cada individuo puede compartir una porción de la vivencia de un entorno más o menos lejano a través de otro. Lo que no explicita es que esa experiencia se produce a través de una codificación virtualizada de la esencia de esa experiencia. Y ni falta que hace, pues Google y los potenciales usuarios del producto ya han sumido que lo virtual es lo real, sin ninguna fisura en la que pueda filtrarse la duda, sin titubeos. Esa es la mediación que nos espera en el mañana que ya es hoy. La que asesina y esconde el cadáver de las sensaciones que se abren en el cuerpo cuando por fin culminamos el ascenso a una montaña y oteamos el horizonte, para convencernos de que la visualización de esa pequeña gesta a través de un dispositivo es tan buena o mejor. Solo la preservación de la corporeidad, de la primera persona en nuestras acciones unida al empleo consciente y mediador de una cultura eternamente incompleta, imperfecta, puede darnos la verdadera medida de nuestra presencia en el mundo. La última baza que nos queda antes de encontrarnos cara a cara frente a nuestro reflejo.

\section{REFERENCIAS}

Baudrillard, Jean (1981). Simulacres et simulations. París: Éditions Galilée.

Baudrillard, Jean (1995). El crimen perfecto. Edición digital por Minicaja.

Baudrillard, Jean (2006). El complot del arte: ilusión y desilusión estéticos. Amorrortu.

Baudrillard, Jean (2009). La sociedad de consumo. Sus mitos, sus estructuras. Madrid: Siglo XXI.

Benjamin, Walter (2003). La obra de arte en la época de su reproductibilidad técnica México: Ítaca.

Bloom, Harold (2002). El futuro de la imaginación. Barcelona: Anagrama. 
Calvino, Italo (1995). Seis propuestas para el próximo milenio. Madrid: Ediciones Siruela.

Debord, Guy (1967). La sociedad del espectáculo. Edición digital por Minicaja.

Debord, Guy-Ernest y Woman, Gil J. (1956). «Mode d'emploi du détournement». Les lèvres nues, n. 8, mayo de 1956. Recuperado de

$\underline{\text { http://sami.is.free.fr/Oeuvres/debord_wolman_mode_emploi_detournement.html }}$

Marcus, Greil (2011). Rastros de carmin: una historia secreta del siglo XX. Barcelona: Anagrama.

Žižek, Slavoj (2005). Bienvenidos al desierto de lo real. Madrid: Akal.

\section{AUTOR}

\section{Jordi Revert}

Es doctorando en Comunicación en la Universitat de València y completó el Máster en Interculturalidad, Comunicación y Estudios Europeos del mismo centro. Desde 2008 ejerce su labor profesional como crítico y escritor cinematográfico en medios online (LaButaca.net, Détour, Efe Eme) y ha publicado numerosos artículos en revistas científicas. Desde 2009 forma parte del Consejo de Redacción de L'Atalante. Revista de estudios cinematográficos y desde 2015 dirige la publicación. En 2016 publicará su primer libro, un estudio sobre el director Paul Verhoeven. Ha impartido diversos cursos y seminarios universitarios sobre aspectos relacionados con el cine y el periodismo.

\section{https://uv.academia.edu//JordiRevert}

